\title{
THE ROLE OF SURFACE MICROTOPOGRAPHY IN THE MODULATION OF OSTEOBLAST DIFFERENTIATION
}

\author{
J.S Hayes ${ }^{1,2}$, I.M Khan ${ }^{2}$, C.W Archer ${ }^{2}$, and R.G Richards ${ }^{1,2}$. \\ ${ }^{1} \mathrm{AO}$ Research Institute Davos, Switzerland \\ 2. Cardiff School of Biosciences, Cardiff University, Wales, UK
}

\begin{abstract}
The osteoinductive and conductive capabilities of commercially pure titanium and its alloys is well documented, as is their ability to provide long-term stability for permanent implantable devices. Fracture fixation in paediatric and trauma patients generally requires transient fixation after which the implant becomes redundant and requires removal. Removal can be complicated due to excessive bony over-growth which is encouraged by the standard micro-rough implant surface. We have shown in vivo that removal related morbidity can be significantly reduced with surface polishing, a technique which reduces the micro-roughness of clinically available materials. However, tissue integration at the bone-implant interface requires activation of key regulatory pathways which influences osteoblastic differentiation and maturation therefore we do not believe this effect to be purely mechanical. To elucidate potential mechanisms by which surface polishing exerts its effect on bone regeneration this study assessed in vitro the effect of surface polishing commercially pure titanium on cell growth, morphology and on the regulation of core binding factor 1 , osterix, collagen I, alkaline phosphatase, bone sialoprotein and osteocalcin for primary rat calvarial osteoblasts. Results indicate that polishing differentially influences osteoblast differentiation in a surface dependent manner and that these changes are potentially linked to surface dependent morphology, but not to differences in cell proliferation.
\end{abstract}

Keywords: Titanium, gene expression, surface modification, osteoblast differentiation, cell morphology.

*Address for correspondence

Jessica Hayes

AO Research Institute Davos,

Clavadelerstrasse 8 ,

7270 Davos, Switzerland.

Telephone Number: +41 814142397

FAX Number: +41 (0)81 4142288

E-mail: jessica.hayes@aofoundation.org
Introduction

While the necessity of osseointegration is indisputable for long-term implanted devices such as spine cages and hip and knee replacements, the occurrence of excessive bony on-growth can be a major stumbling block for temporary implant device removal and contributes to approximately $13 \%$ of all removal related morbidity (Alzahrani et al., 2003; Peterson, 2005). The majority of internal fixation devices are produced for clinics with a standard micro-rough finish, and it is this surface that we (Welton, 2007; Schlegel et al., 2008; Pearce et al., 2008; Hayes et al., 2009; Hayes et al., 2010) and others (Degasne et al., 1999; Yang et al., 2003; Arcelli et al., 2007; Guo et al., 2007) have shown to be a major determinant in the type, and extent of tissue integration. With this in mind, recent work in our laboratory has focused on reducing the excessive bone on-growth on clinical materials for ease of removal via manipulation of the implant surface (Pearce et al., 2008; Hayes et al., 2009; Hayes et al., 2010). Specifically, in relation to bone, we have shown that by reducing the microtopography of screws with surface polishing, both the mean removal torque and percentage of bone contact can be significantly reduced in both cortical and cancellous bone after 18 weeks implantation in a sheep model (Pearce et al., 2008). We have shown that following 18 months implantation in sheep that the extraction force required for removal of intramedullary (IM) nails can also be significantly reduced with surface polishing (Hayes et al., 2009). More recently we showed that the removal torque of polished screws from polished locking compression plates (LCPs) was significantly lower compared to clinically used, standard micro-rough constructs after 6,12 and 18 months implantation within sheep (Hayes et al., 2010). However, we do not believe this affect to be purely mechanical.

Osseointegration at the bone-implant interface requires activation of key regulatory pathways which influence osteoblastogenesis, promotion of osteoblastic differentiation and maturation, and finally bone repair/ regeneration. Investigating the effect of surface microtopography on changes in gene expression may therefore, provide information into the regulatory mechanisms behind bone formation at the bone-implant interface. A myriad of studies investigating alterations in cellular behaviour patterns such as; adhesion, morphology, DNA synthesis, integrin and extracellular matrix gene expression, and enzyme activity have been carried out in vitro to elucidate the finer elements of the osteoblast response to materials used in fracture fixation (Martins et al., 1995; Gronowicz and McCarthy, 1996; Kieswetter et al., 1996; Degasne et al., 1999; Lohmann et al., 2002). 
However, changes in molecular events such as gene expression that occur at the cellular level during bony integration are largely undetermined. Previous studies have implicated the influence of surface microtopography in preosteoblast lineage determination (Schneider et al., 2004), and its affect as potentially enhancing osseointegration (Schneider et al., 2003; Masaki et al., 2005; Isa et al., 2006; Guo et al., 2007), and in particular the identification of perceived 'roughness response' genes which are postulated to be differentially expressed on surfaces of varying micro-roughness' (Brett et al., 2004; Arcelli et al., 2007).

The commonality of these previously cited studies is their desire to enhance osseointegration, whereas the aim of this study is to investigate the effect of surface polishing for the purpose of minimising osseointegration. Specifically the aim is to evaluate surface polishing of commercially pure titanium on osteoblast cell growth, cell morphology, and to elucidate potential mechanisms by which surface polishing exerts its effect on a variety of key factors for bone regeneration.

\section{Materials and Methods}

Standard microrough commercially pure titanium, as used in clinics (cpTi-S - International Organisation for standardisation (ISO), 5832-2) (provided by Synthes, Bettlach, Switzerland) was fabricated (cut from a bar, deburred, ceramic tumbled and acid etched) to make 13 $\mathrm{mm}$ and $50 \mathrm{~mm}$ (used for PCR) diameter discs. The same process was used for the electropolished cpTi (cpTi-EP), and paste polished cpTi (cpTi-PP) implants, with the respective polishing step for all cpTi samples taking place prior to the final surface preparation of anodisation. Electropolished surfaces were produced by immersing the samples in a liquid electrolyte and applying an electric current (Steiger SA, Châtel-St Denis, Switzerland). Paste polished samples were produced by KKS (KKS Ultraschall AG, Steinen, Switzerland) by physical tumbling with ground tree bark. Prior to use samples were packaged individually and steam sterilised at $134^{\circ} \mathrm{C}$ for $20 \mathrm{~min}$.

\section{Surface characterisation}

Quantitative measurements for three separate sample discs were taken using a non-contact white light FRT MicroProfÒ (Standard) with CWL $300 \mu \mathrm{m}$ sensor profilometer (Fries Research \& Technology, Bergisch Gladbach, Germany). Roughness average ( $\mathrm{Ra}$ - arithmetic mean of the absolute values of all points of the profile) was measured from a $0.5 \mathrm{~mm}^{2}$ scan area.

Sample morphology was studied using a Hitachi S4700 (Hitachi High-Technologies, Krefeld, Germany) scanning electron microscope (SEM). Images were taken in secondary electron mode, with an accelerating voltage of $5 \mathrm{kV}$, an emission current of $40 \mu \mathrm{A}$, working distance of $10 \mathrm{~mm}$ and a positive tilt of $10^{\circ}$.

\section{Cell growth}

Rat calvaria (RC) cells isolated by sequential enzymatic digestion (Gerber and ap Gwynn, 2001) from 6 day old neonatal Swiss Wistar rats were seeded at a density of 10,000 cells/disc in Dulbecco's Modified Eagle's medium (DMEM; Gibco/Invitrogen, Paisley, UK) containing 10\% foetal calf serum (FCS), $50 \mu \mathrm{g} / \mathrm{mL}$ of ascorbic acid, 10 $\mathrm{nM}$ dexamethasone, $5 \mathrm{mM} \beta$-glycerophosphate, and $1 \%$ penicillin-streptomycin in 24 well plates (Corning, Lowell, MA, USA) for $1,2,4,6,8,10,14$ and 21 days. Plates were incubated at $37^{\circ} \mathrm{C}$ with an atmosphere of $5 \% \mathrm{CO}_{2}$ and $95 \%$ humidity. A total of six samples per time point were included. Media was aspirated from the wells and the samples were washed three times with $500 \mu \mathrm{L}$ of 0.1 $\mathrm{M}$ phosphate buffered saline (PBS) solution (Sigma, St. Louis, MO, USA). After rinsing, $500 \mu \mathrm{L}$ of $0.1 \mathrm{M}$ PBS containing $300 \mathrm{U} / \mathrm{ml}$ of collagenase type I (Worthington, Lakewood, NJ, USA) and trypsin-EDTA (Gibco) were added to each well. Culture plates were incubated at $37^{\circ} \mathrm{C}$ with an atmosphere of $5 \% \mathrm{CO}_{2}$ and $95 \%$ humidity for approximately $5 \mathrm{~min}$. After this time had elapsed, $500 \mu \mathrm{L}$ of DMEM containing FCS was added to each well to stop the reaction. A $50 \mu \mathrm{L}$ aliquot of each sample was transferred to a haemocytometer. Two separate counts per sample were performed, resulting in 12 measurements per sample type/ time point. Data presented are from one of 3 separate experiments.

\section{Immunolabelling of cytoskeletal components actin, vinculin and tubulin}

All volumes were $500 \mu \mathrm{L}$ unless otherwise stated. RC cells were seeded at a density of 1000 cells/disc in 24 well plates (Corning) for $24 \mathrm{~h}$. Two samples of each test substrate were included for qualitative analysis. Each experiment was repeated a minimum of 3 times. After a $24 \mathrm{~h}$ incubation period, samples were washed three times for $1 \mathrm{~min}$ per wash with $0.1 \mathrm{M}$ Piperazine-NN'-bis-2-ethane sulphonic acid (PIPES), pH 7.4 after which time they were permeabilised for 2 min with $0.1 \%$ Triton-X in $0.1 \mathrm{M}$ PIPES. For $1 \mathrm{~min}$ subsequent to this samples were fixed using $0.5 \%$ glutaraldehyde. Samples were washed 3 times for 2 minutes with $0.1 \mathrm{M}$ PIPES. To block from nonspecific labelling, 1:20 dilution of goat serum in $0.1 \mathrm{M}$ PBS, was added to the wells for $30 \mathrm{~min}$. Primary antibodies were added to each well at a final volume of 1:800 mouse monoclonal anti-vinculin (V9131; Sigma) or 1:200 mouse anti- $\beta$ tubulin (T4026; Sigma) with 1:50 Rhodamine conjugated phalloidin (R415; Molecular probes, Eugene, OR, USA) suspended in a 1:20 dilution of goat serum in $0.1 \mathrm{M}$ PIPES, and were kept overnight at $2-8^{\circ} \mathrm{C}$ wrapped in aluminum foil. Subsequently, samples were washed twice for 5 min with $0.1 \mathrm{M}$ PIPES after which time, the secondary antibody (Alexaflour 488, goat anti-mouse IgG (Molecular Probes), final dilution of $10 \mu \mathrm{g} / \mathrm{mL}$ ) was added for $45 \mathrm{~min}$ at room temperature protected from light. Finally, samples were washed 3 times for 2 minutes each with $0.1 \mathrm{M}$ PIPES. Approximately $10 \mu \mathrm{L}$ of Prolong antifade reagent with DAPI (4,6-diamidino-2-phenylindole; Molecular Probes) was added to the samples, which were then enclosed with a glass cover-slip. Samples were imaged using a Zeiss laser scanning microscope 510 (Zeiss Microimaging, Göttingen, Germany). 


\section{RNA Isolation}

RC cells were seeded at a density of 100,000 cells $/ 50 \mathrm{~mm}$ sample in $60 \mathrm{~mm}$ Petri-dishes (Corning). Cells were incubated at $37^{\circ} \mathrm{C}$ with a $5 \% \mathrm{CO}_{2}$ atmosphere for $48 \mathrm{~h}, 7$, 14 and 21 days. Data presented are from one of 3 separate experiments. Values are \pm standard error of the mean (S.E.M) of four independent cultures per sample at each time point. Samples were rinsed three times with $0.1 \mathrm{M}$ PBS, pH 7.4. Then, $600 \mu \mathrm{L}$ of TRI-reagent (Sigma), supplemented with $5 \mu \mathrm{L}$ of Polyacryl Carrier ${ }^{\mathrm{TM}}$ (Molecular Research Center, Cincinnati, OH, USA) was added directly to the sample. After adding $300 \mu \mathrm{L}$ of 1-bromo-3-chloropropane (Sigma) and centrifuging at $12000 \mathrm{~g}$ for $15 \mathrm{~min}$ at $4^{\circ} \mathrm{C}$, in an Eppendorf 5417R centrifuge (Eppendorf, Hamburg, Germany) $300 \mu \mathrm{L}$ of the aqueous phase was removed and transferred to a new $1.5 \mathrm{ml}$ RNase free tube (Eppendorf). Then, $0.25 \mathrm{ml}$ of $100 \%$ isopropanol (Fluka/ Sigma) and $0.25 \mathrm{ml}$ of a high salt precipitation solution $(0.8 \mathrm{M}$ sodium citrate and $1.2 \mathrm{M} \mathrm{NaCl}$ ) (Molecular Research Center) were added and mixed by inversion. Samples were stored at room temperature for $10 \mathrm{~min}$ and then centrifuged for $8 \mathrm{~min}$ at $12000 \mathrm{~g}$ at $4^{\circ} \mathrm{C}$. Afterwards, $600 \mu \mathrm{L}$ of $75 \%$ ethanol was added directly to the sample. The sample was then applied to the Qiagen RNeasy column, and processed according to manufacturer's instructions (Qiagen, Alameda, CA, USA). The purity of the RNA was assessed using $\mathrm{A}_{260 / 280 \mathrm{~nm}}$ measurements using the Nanodrop system (Witec, Littau, Germany) and associated software.

\section{Reverse transcription}

All reagents were supplied by Applied Biosystems (Carlsbad, CA, USA). For each reverse transcription reaction a Mastermix of $100 \mu \mathrm{L}(70 \mu \mathrm{L}$ of reagents and 30 $\mu \mathrm{L}$ of RNase free water containing $2 \mu \mathrm{g}$ of RNA sample) was added to a $0.2 \mathrm{ml}$ reaction tube. The reaction mix consisted of $10 \mu \mathrm{L}$ of 10x TaqMan RT Buffer, $22 \mu \mathrm{L}$ of 25 $\mathrm{mM}$ Magnesium chloride, $20 \mu \mathrm{L}$ of DeoxyNTPs mixture (2.5 mM dATP, dCTP, dGTP, dTTP), and $5 \mu \mathrm{L}$ of Random Hexamers $(50 \mu \mathrm{M})$. Next, $2.5 \mu \mathrm{L}$ of Multiscribe Reverse Transcriptase $(50 \mathrm{U} / \mu \mathrm{L})$ and $2 \mu \mathrm{L}$ of the RNase inhibitor $(20 \mathrm{U} / \mu \mathrm{L})$ were added. The solution was made up to the desired amount by adding RNase free water supplemented with $2 \mu \mathrm{g}$ RNA. Samples underwent reverse transcription in a GeneAmp 5700 SDS instrument (Applied Biosystems) for $10 \mathrm{~min}$ at $25^{\circ} \mathrm{C}$ for primer incubation, $30 \mathrm{~min}$ at $48^{\circ} \mathrm{C}$ for reverse transcription, and $5 \mathrm{~min}$ at $95^{\circ} \mathrm{C}$ for reverse transcriptase inactivation.

\section{Real time quantitative polymerase chain reaction (qPCR)}

Primers for the house keeping gene 18S, osterix (osx), core binding factor 1 (Cbfa1), alkaline phosphatase (ALP), bone sialoprotein (BSP), osteocalcin (OCN), and collagen type I (COLI) were purchased from PrimerDesign (Southampton, UK) (Table S1 - supplementary data). Five microliters of cDNA templates were transferred into a clear thermo-fast ${ }^{\circledR} 96$ well detection plate (ABgene, Epsom, UK) with a reaction mix containing $1 \mu \mathrm{L}$ of primer mix (PrimerDesign; final concentration of $200 \mathrm{nM}$ ); $10 \mu \mathrm{L}$ of 2x master mix of SYBR green (PrimerDesign) and made up to a total of $20 \mu \mathrm{L}$ with double distilled water containing DEPC. The plate was then covered with a thermostable RNase-free cover-slip (Milian, Geneva, Switzerland), centrifuged for 30 seconds in a Rotanta 46 plate centrifuge (Hettich, Tuttlingen, Germany), and transferred to an Applied Biosystems 7500 thermocycler. The plate was run once at $95^{\circ} \mathrm{C}$ for $10 \mathrm{~min}$ followed by $95^{\circ} \mathrm{C}$ for $30 \mathrm{~s} ; 60^{\circ} \mathrm{C}$ for $1 \mathrm{~min}$ and $72^{\circ} \mathrm{C}$ for $1 \mathrm{~min}$ for 40 cycles; the dissociation curve included incubation of the plate at $95^{\circ} \mathrm{C}$ for $15 \mathrm{~s}$, $60^{\circ} \mathrm{C}$ for $1 \mathrm{~min}$ and finally $95^{\circ} \mathrm{C}$ for $15 \mathrm{~s}$. A no template control containing the same reagents minus cDNA template was included for each plate as a negative control.

\section{Data analysis}

Relative quantification $\left(2^{-\mathrm{DD}} \mathrm{Ct}\right.$; Livak and Schmittgen, 2001) was used to assess the fold change in gene expression over time. The level of specific mRNA was calculated by subtracting $\mathrm{Ct}$ values of the control gene (18s RNA) from the CT values of specific gene of interest at the time point in question $(7,14$ or 21 days). The levels of each gene of interest after 48 hours culturing on specific sample type were taken as 1.0 and were used to identify the relative fold changes in expression after 7, 14 and 21 days culturing on the same sample type.

\section{Statistical analysis}

Statistical evaluations were made using SPSS for Windows version 14.0 (SPSS Inc, Chicago, IL). The non-parametric Kruskall-Wallis test was performed to analysis cell number data. To delineate differences relating to gene expression over time, Univariate ANOVA was performed with Bonferroni post-hoc tests. Values of $p \leq 0.05$ were regarded as significant.

\section{Results}

\section{Surface characterisation}

The reduction in surface microtopography due to polishing is demonstrated with SEM (Fig. 1). The roughness average (Ra) of all samples as determined by white light profilometry is also noted as insets within the respective SEM image. While the Ra of cpTi-EP was noted to be akin to that of cpTi-S, SEM analysis demonstrates an undulating surface, with heterogeneous distribution. With higher magnification, the smoothness of the surfaces becomes more apparent.

\section{Cell growth}

All sample types appeared to support a similar rate of growth over the time period studied. However, it was noted that peak in growth for polished samples appeared to occur by day 14 , whereas the highest number of cells on cpTi-S samples was noted after 10 days culturing. Statistically, however, surface polishing of cpTi was not found to significantly alter cell number compared to cpTi-S $(p=0.874)$.

\section{Immunolabeling of cytoskeletal components actin, vinculin and tubulin}

Confocal microscopy analysis showed that cpTi-S appeared to restrict the cell body to generally a cuboidal 

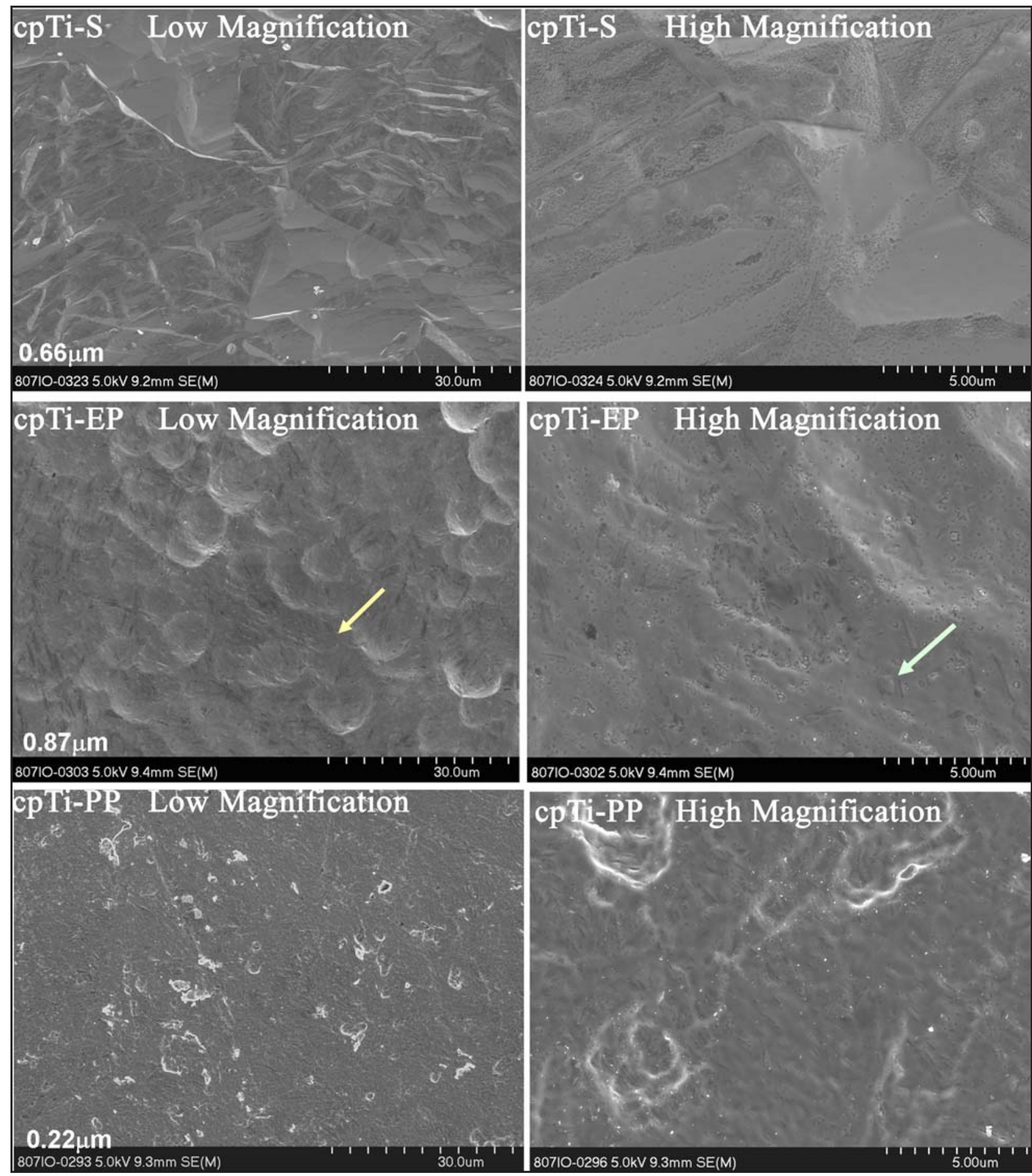

Fig. 1. SEM images for cpTi-S, cpTi-EP and cpTi-PP. Variations in height of the grain boundaries/orientation on the cpTi-S surface produce an irregular surface morphology. While the Ra of cpTi-EP was noted to be akin to that of cpTi-S, SEM analysis demonstrates an undulating surface, with heterogeneous distribution. In some areas, the pits are not present (yellow \& green arrows). With higher magnification, the smoothness of the surfaces becomes more apparent. Paste polishing reduced the micro-topography associated with cpTi-S, to produce a weaved pattern with evident nano-topography. Inset - Roughness average of the samples expressed in micrometers.

morphology with some extending filopodia (Fig. 3). Moreover, the periphery of the cells appeared to be influenced by the micro-topographical features of the surface often being shaped by the changes in height or shape of the surface (Fig. 3, inset; blue arrow). Cells on cpTi-EP samples adopted a more 'fibroblast-like' triangular shape with three large lamellapodia akin of that observed for fibroblast cells. Cells on cpTi-EP appeared better spread than cells on cpTi-S and had an elongated cell body. Also, cells on cpTi-EP appeared unhindered by the small alterations in micro-topography, unlike cpTi-S (Fig. 3 inset; yellow arrow). Cells cultured on cpTi-PP samples had an elongated triangular morphology, similar to cpTi-EP, and appeared flattened compared to cells cultured on cpTi-S. For cpTi-PP it was observed that actin filaments along the cell periphery contributed to the arched appearance noted 


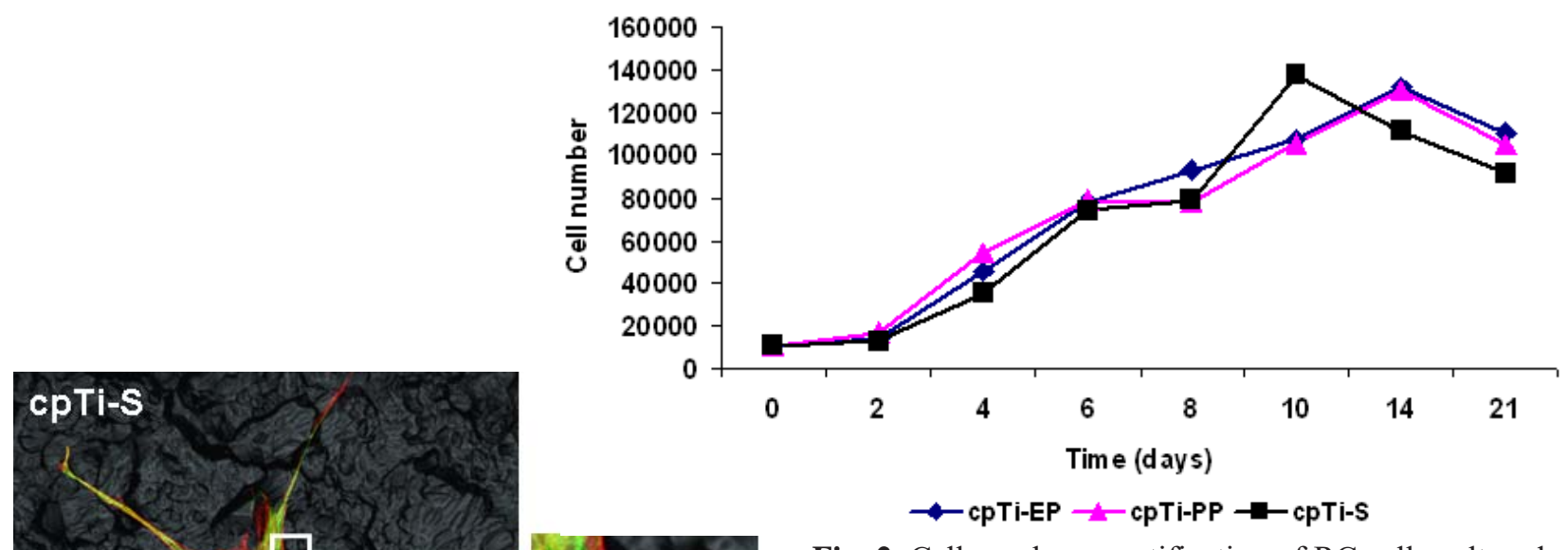

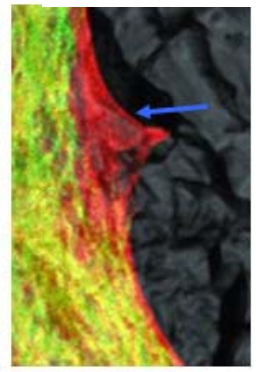
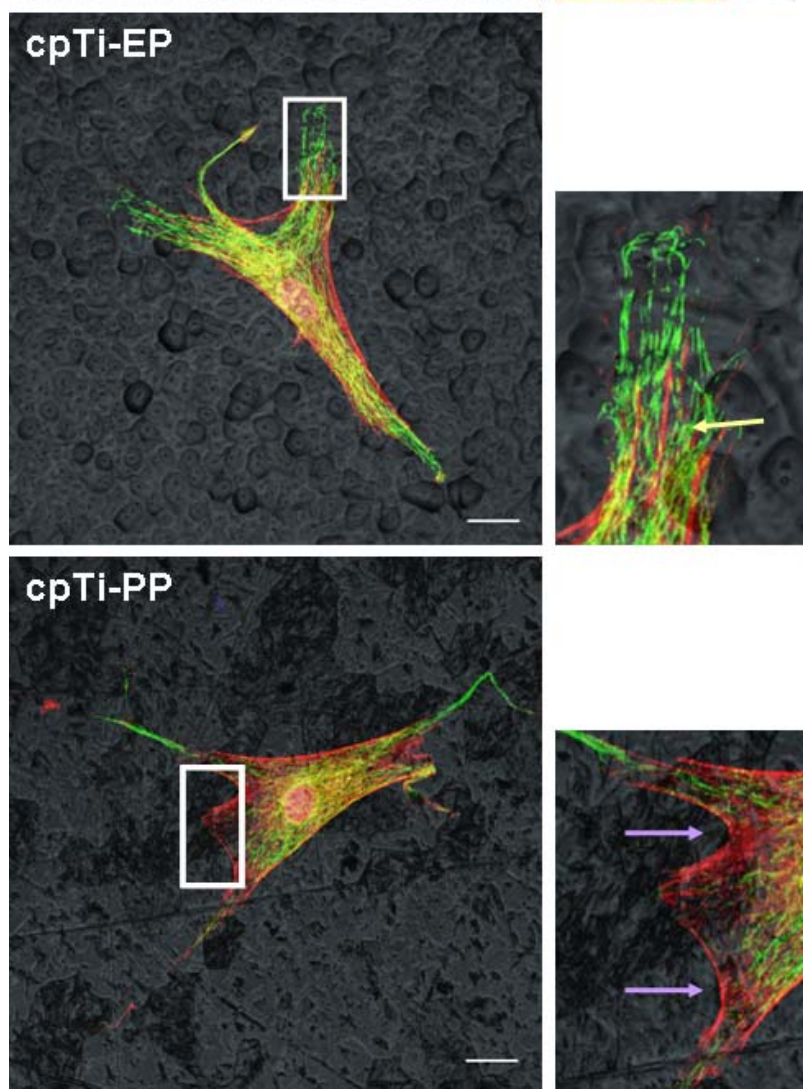

Fig. 3. RC cells cultured on cpTi-EP, cpTi-PP and cpTi-S for $24 \mathrm{~h}$. Cells were fluorescently labelled for actin (red) and tubulin (green). Cell nuclei were labelled using DAPI (pink/purple). The surface micro-discontinuities of cpTi$\mathrm{S}$ induced a cuboidal cell body morphology. The actin filaments at the cell periphery appeared to be manipulated by the surface interaction (white \& blue arrows). Cells cultured on cpTi-EP and cpTi-PP displayed an elongated, spindle shaped morphology. Cells cultured on polished cpTi samples did not appear to be restricted by small changes in the surface morphology (yellow and purple arrows). Scale bar $=20 \mu \mathrm{m}$.
Fig. 2. Cell number quantification of RC cells cultured on cpTi-S, cpTi-EP and cpTi-PP. Surface polishing was not found to significantly affect cell number for cpTi ( $p=0.874)$ samples.

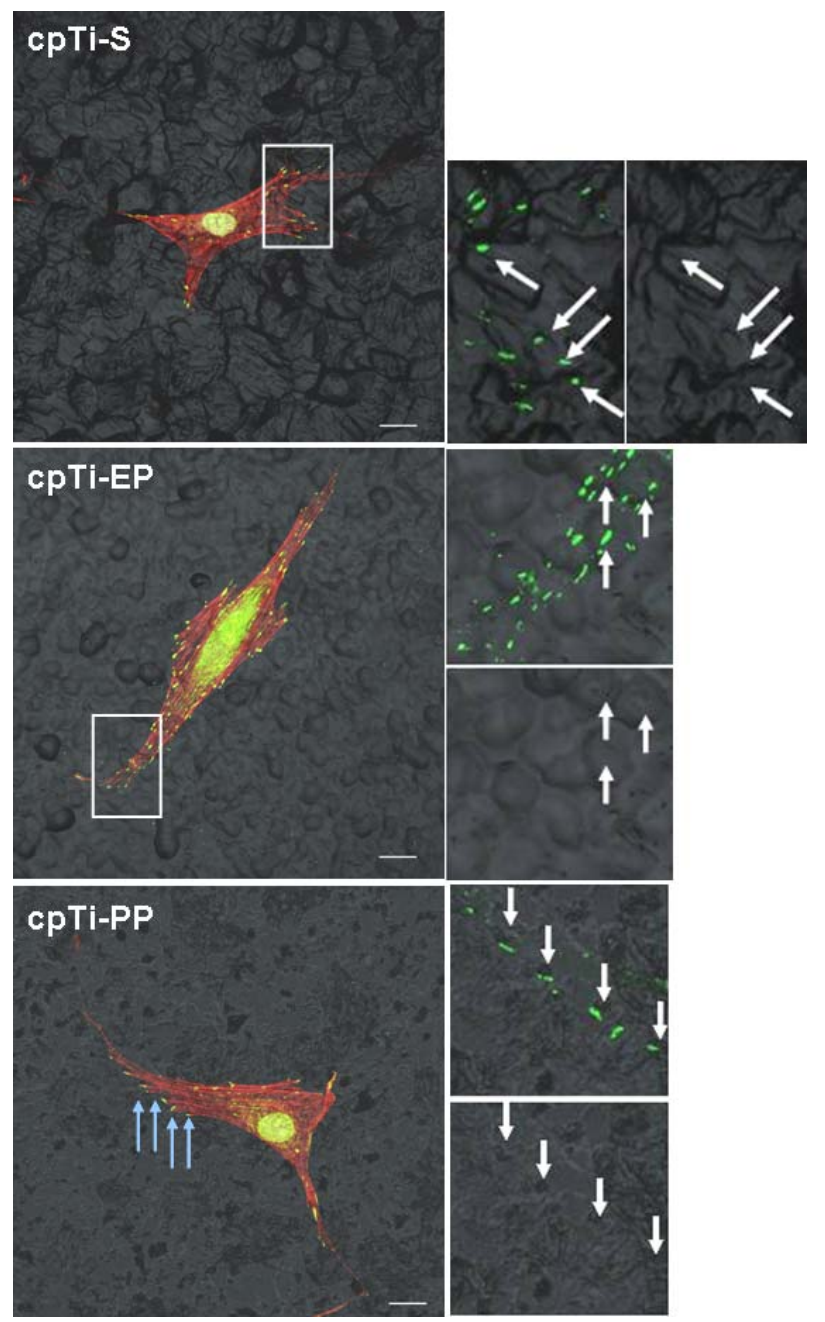

Fig. 4. RC cells cultured on cpTi-EP, cpTi-PP and cpTi$\mathrm{S}$ for 24 hours. Cells were fluorescently labelled for actin (red) and vinculin (green). Cell nuclei were labelled using DAPI (pink/purple). FA sites on cpTi-S surfaces appeared regulated by variations in topography (cpTi-S; white arrows), and appeared frequently on peaks of the surface. In contrast, cpTi-EP had very little influence on FA placement, and transverse variations topography. For cells cultured on cpTi-PP, focal adhesions sites appeared sensitive to small changes on a nano-metric level. Scale bar $=20 \mu \mathrm{m}$. 


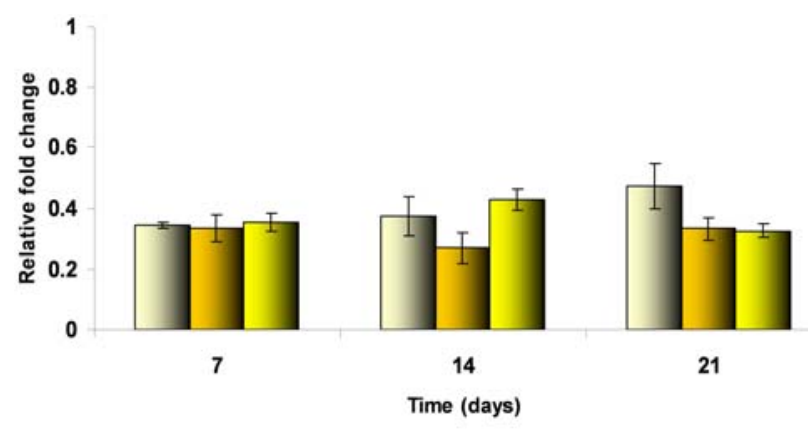

a cPTi-EP a cpTi-PP a cpTi-S

Fig. 5. Collagen I expression for RC cells cultured on cpTi samples. Neither surface polishing treatment of cpTi had a significant influence on COL1 expression at any time point compared to cpTi-S samples. Values are the mean \pm S.E.M of four independent cultures per sample type at each time point.

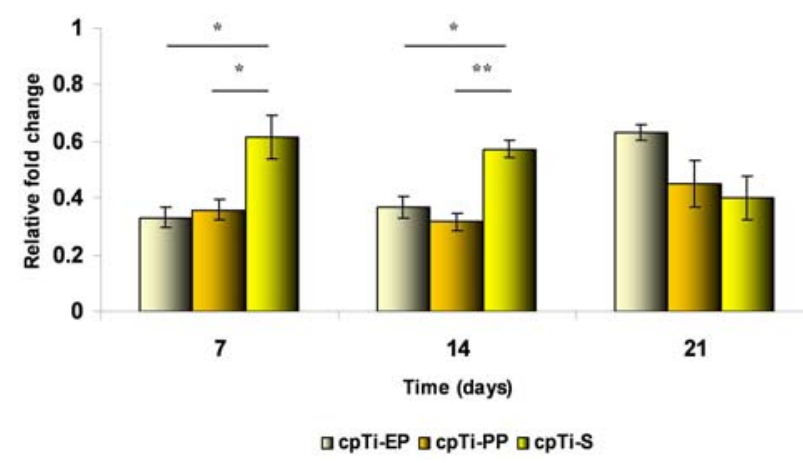

Fig. 7. Osterix expression for RC cells cultured on cpTi samples. After 7 and 14 days cpTi-EP and cpTi-PP significantly decreased expression compared to cpTi-S. $\left({ }^{*} p<0.05 ; * * p<0.01 ; * * * p<0.001\right)$. Values are the mean \pm S.E.M of four independent cultures per sample type at each time point.

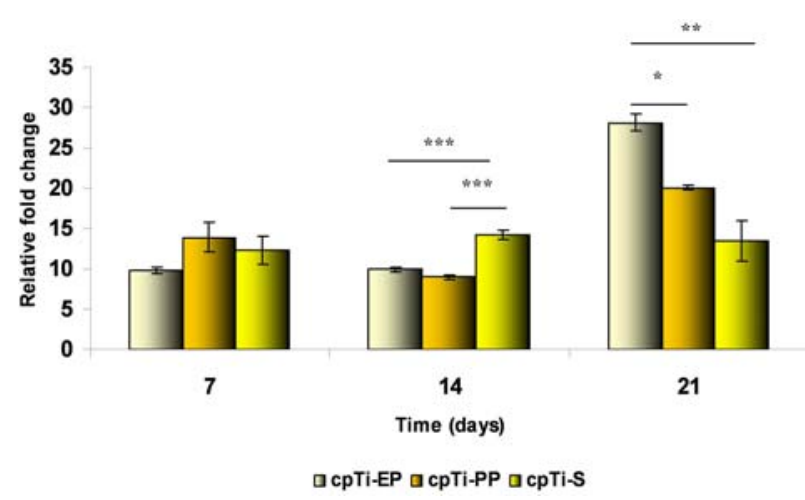

Fig. 9. Bone Sialoprotein expression for RC cells cultured on cpTi samples. After 14 days BSP expression was significantly decreased on cpTi-EP and cpTi-PP compared to cpTi-S. After 21 days BSP expression was significantly higher on cpTi-EP samples compared to both cpTi-S and cpTi-PP samples. $\left({ }^{*} p<0.05\right.$; $* *<<0.01$; $* * * p<0.001)$. Values are the mean \pm S.E.M of four independent cultures per sample type at each time point.

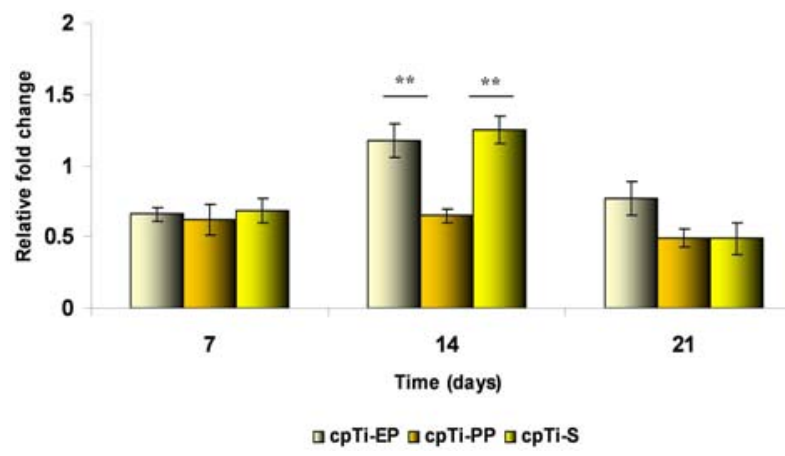

Fig. 6. Cbfa-1 expression for RC cells cultured on cpTi samples. Cbfa-1 expression was significantly decreased on cpTi-PP samples compared to both cpTi-EP and cpTi$\mathrm{S}$ samples after 14 days. Electropolishing was not found to significantly influence Cbfa-1 compared to cpTi-S. $(* p<0.05 ; * * p<0.01 ; * * * p<0.001)$. Values are the mean \pm S.E.M of four independent cultures per sample type at each time point.

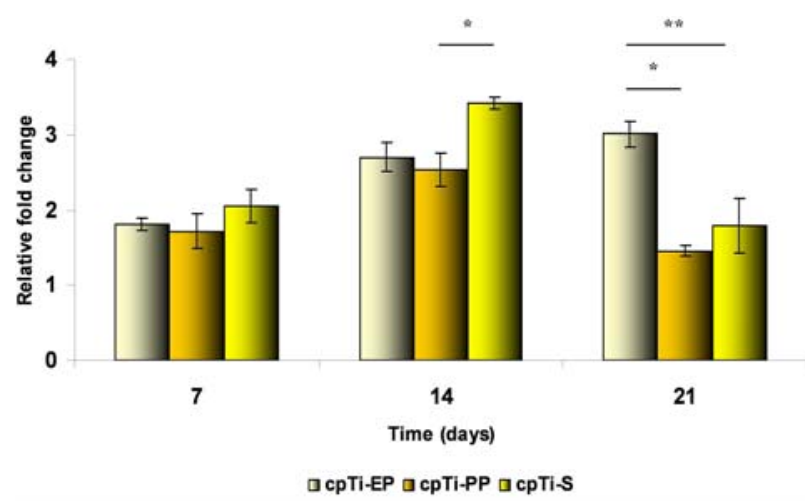

Fig. 8. Alkaline phosphatase expression for RC cells cultured on cpTi samples. Electropolishing of cpTi was not significantly reduced compared to cpTi-S. After 21 days cpTi-EP was observed to significantly increase ALP expression compared to cpTi-PP and cpTi-S. In contrast, paste polishing of cpTi was found to significantly reduce ALP expression after 14 days. $(* p<0.05 ; * * p<0.01$; $* * * p<0.001)$. Values are the mean \pm S.E.M of four independent cultures per sample type at each time point.

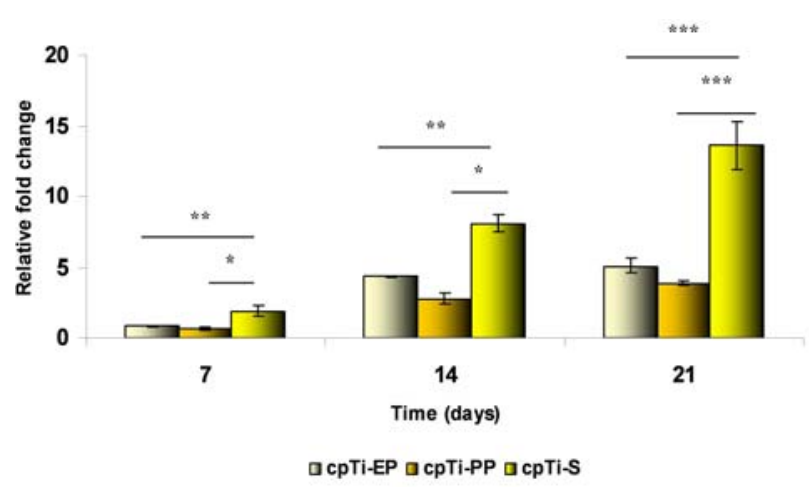

Fig. 10. Osteocalcin expression for RC cells cultured on cpTi samples. After 7, 14 and 21 days OCN expression was significantly reduced on cpTi-EP and cpTi-PP compared to cpTi-S samples. $\left({ }^{*} p<0.05\right.$; $* * p<0.01 ; * * * p<0.001)$. Values are the mean \pm S.E.M of four independent cultures per sample type at each time point. 


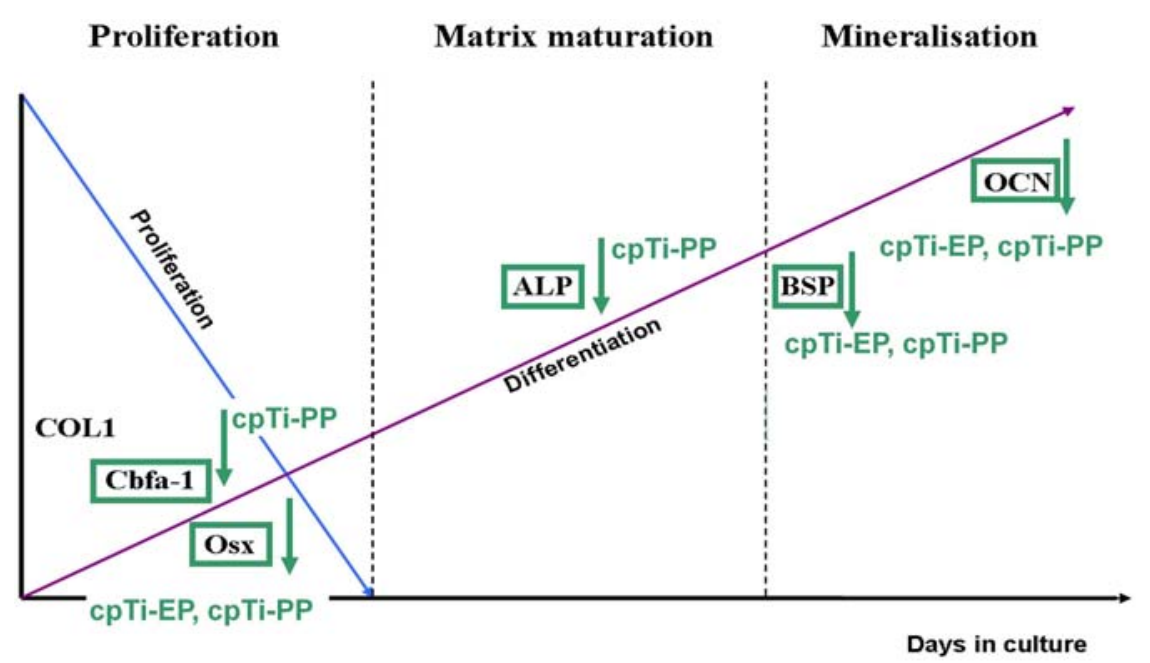

Fig. 11. Schematic representation of the genes/transcription factors significantly reduced by surface polishing of cpTi. Green boxes and arrows represent factors that are significantly reduced compared to standard microrough sample cpTi. The specific polished samples responsible for this reduction are noted. Adapted from Lian and Stein (1992).

(Fig. 3; purple arrow) perhaps resulting from interaction with surface micro-topography.

We noted that focal adhesion (FA) sites are also influenced by the changes in micro-roughness of cpTi-S. Specifically, FA sites were frequently observed on the edges of a micro-discontinuity which may be one reason for the less spread appearance compared to polished samples (figure 4, cpTi-S white arrows). As noted previously, the surface topography of cpTi-EP had very little influence on restricting cell spreading and was also noted here to have little effect on focal adhesion placement (Fig. 4, cpTi-EP white arrows) and these structures were regularly noted to transverse the small variations in topography. While the tubulin and actin networks did not appear to hindered by the small variations in microtopography the focal adhesions sites of cells cultured on cpTi-PP appeared to be sensitive to small changes on a nano-metric level (Fig. 4; cpTi-PP, blue and white arrows).

\section{Analysis of gene expression}

Due to the amount of data generated by univariate analysis of variance statistical analyses only the principal significant findings will be presented from this point. The reader is directed to the supplementary data for a full, comprehensive outline of statistical findings. Graphs for Collagen I (Fig. 5), Cbfa-1 (Fig. 6), Osterix (Fig. 7), ALP (Fig. 8), BSP (Fig. 9) and OCN (Fig. 10) represent the time dependent changes observed in mRNA levels. A summary of the results can be found in Fig.11.

\section{Electropolished cpTi}

The change in micro-topography of cpTi appeared to most significantly influence osteoblast terminal differentiation, as assessed by OCN expression. Specifically, electropolished cpTi samples significantly decreased OCN expression compared to standard micro-rough cpTi after $7(p=0.030), 14(p=0.004)$ and 21 days culturing $(p<0.001)$. Concurrently, BSP expression was significantly reduced on electropolished cpTi after 14 days $(p<0.001)$. This effect of electropolishing on OCN expression appeared to by also associated with a significant decrease in Osx expression on polished versus micro-rough cpTi after $7(p=0.019)$ and $14(p=0.019)$ days. Interestingly, after 21 days electropolished cpTi was observed to induce a significant increase in both ALP $(p=0.032)$ and BSP $(p=0.002)$ expression compared to micro-rough cpTi. Neither COL1 nor Cbfa-1 expression appeared to be significantly influenced by electropolishing.

\section{Paste polished cpTi}

Similar to its electropolished counterpart, paste polished cpTi samples significantly decreased OCN expression compared to standard micro-rough cpTi after $7(p=0.004)$, $14(p<0.001)$ and 21 days culturing $(p<0.001)$. Also similar to electropolished cpTi, this reduction in OCN expression on paste polished samples was associated with a significant decrease in Osx expression after $7(p=0.040)$ and 14 days $(p=0.006)$ and BSP expression after 14 days $(p<0.001)$. However, paste polishing of cpTi appeared to differentially affect Cbfa-1 and ALP expression, as mRNA levels for both these genes (Cbfa-1 $(p=0.003)$; ALP $p=0.029)$ were significantly reduced compared to micro-rough $\mathrm{cpTi}$ after 14 days. This latter trend was not observed for electropolished cpTi samples. Results suggest that COL1 expression was not influenced by cpTi paste polishing.

\section{Discussion}

Excessive bony on-growth of a device has been identified as one of the main clinical problems associated with implant removal morbidity. Micro-rough implant surfaces have been shown extensively to be a major determinant in the type and extent of hard tissue integration of the device (see Hayes and Richards, 2010, for review). We have recently shown in vivo that surface polishing; a method used to effectively 'smoothen' the surface of an implant material, can help alleviate extraosseous formation (Pearce et al., 2008; Hayes et al., 2009; Hayes et al., 2010). This in vitro study was performed to investigate if these observations were translated to a cellular level and to elucidate potential mechanisms by which surface polishing exerts its effect on a variety of key factors for bone regeneration. 
In this study, a significant decrease in OCN mRNA was noted for electro- and paste polished samples at each time point studied. While the function of this bone matrix protein is still under scrutiny, several studies suggest that OCN principally functions in the later stages of osteoblast terminal differentiation by inhibiting further mineralisation in vitro (Boskey et al., 1985; Hunter et al., 1996) and by activating and promoting osteoclast differentiation in vivo (Glowacki and Lian, 1987). Thus, the significant decrease in OCN mRNA on polished samples compared to microrough counterparts would indicate that a longer period is required for cells cultured on polished samples before terminal differentiation is induced. Boyan et al. (2002) have also previously demonstrated a surface dependent increase in osteoblast mediated mineral deposition in vitro. We too have observed increased matrix production over a 21 day culture period on micro-rough samples compared to polished variants, as determined by calcium-45 incorporation (data not shown). More recently, Olivares-Navarette et al. (2010) have demonstrated a surface roughness dependent increase in OCN expression for mesenchymal stem cells cultured on smooth $(0.08 \mu \mathrm{m})$ versus microrough $(3.22 \mu \mathrm{m}) \mathrm{cpTi}$ samples. Thus, in agreement with our results, it appears that microtopography may be sufficient to also induce mesenchymal stem cell differentiation towards an osteoblast phenotype at an accelerated rate compared to similar material with a smooth surface. This roughness related increase in terminal differentiation has also been reported elsewhere (Schneider et al., 2004; Balloni et al., 2009; Mendonça et al., 2010). The decrease in OCN expression observed for polished samples in this study also correlates with mechanical and histological data accrued from studies investigating the same materials in vivo that showed a lower percentage of bone contact adjacent to polished devices at time points spanning weeks and months (Pearce et al., 2008; Hayes et al., 2010).

The initial interactions leading to the observed reduction in OCN mRNA levels are less defined. The master gene, Cbfa-1, is known to be a major regulatory determinant of many osteoblast related genes such as OCN (Ducy et al., 1997; Komori et al., 1997; Otto et al., 1997). While paste polished cpTi samples appeared to demonstrate this regulatory link via a reduction in Cbfa- 1 and an associated reduction in OCN, a similar link was not observed for electro-polished cpTi samples. Thus, it would appear that at least for cpTi-EP samples, an alternative signalling mechanism independent of Cbfa-1, alternative Cbfa-1 isoforms (Harada et al., 1999) or binding of Cbfa1 with a co-factor specific for OCN repression (Lamour et al., 2007) may be responsible for the reduction observed.

In contrast, both electro- and paste polished cpTi had significant decreases in osterix expression, a marker for early osteoblast differentiation (Nakashima et al., 2002) at both 7 and 14 days, suggesting therefore, that the microrough cpTi surface may be driving osteoblast differentiation at a quicker rate compared to polished samples. Furthermore, we also observed alterations in mRNA expression of BSP. Recent work has demonstrated that BSP functions directly in promoting osteoblast differentiation resulting in increased matrix production and mineralisation in vitro (Gordon et al., 2007). In this study, a significant reduction in BSP was noted for polished cpTi samples after 14 days. This could indicate that osteoblast differentiation and initiation of matrix mineralisation on these samples is delayed compared to microrough cpTi, which is supported by the decrease in osterix expression and subsequent significant reduction in OCN observed.

After 21 days, polished cpTi samples demonstrated a significant increase in BSP compared to microrough cpTi. This supports our hypothesis that terminal differentiation is reached later on polished samples, compared to the accelerated rate of differentiation observed on microrough samples. Interestingly, ALP mRNA expression was also higher after 14 days culturing on microrough cpTi, although this difference was only observed to be significantly higher compared to paste polished cpTi. In support of this, we have also previously observed a trend for lower ALP protein on polished samples over the same culture period. Similarly, however, these findings were not noted to be statistically significant (data not shown).

Other studies have implicated an inverse relationship between cell number and surface micro-roughness (Martin et al., 1996; Boyan et al., 2002). Specifically, it is suggested that microrough surfaces reduce the capacity for osteoblast proliferation, hence driving osteoblast differentiation. However, we did not observe any significant differences in cell proliferation on polished versus microrough samples, and therefore, do not believe this parameter to be responsible for the changes in expression observed. This is in agreement with several other studies that have not observed surface dependent differences in cell proliferation rate, despite demonstrating a microrough surface dependent increase in osteoblast differentiation (Schneider et al., 2003). Furthermore, we do not believe that surface chemistry was a major determining factor in the differences observed as all samples were anodised as a final processing step and therefore, no differences in surface chemistry were noted ((Table S2 - supplementary data); Hayes et al., 2009; Hayes et al., 2010)

In this study we report substrate dependent changes in cell shape for the surfaces tested. Specifically, cell morphology and distribution of focal adhesion sites appeared to be influenced by the micro-topographical features of the surface, often being shaped by the changes in height or shape of the substrate. For cells cultured on cpTi-S surfaces this involved restricted cell spreading, resulting in the typical cuboidal cell body associated with osteoblasts. Furthermore, focal adhesions were formed predominately at the edges of the microstructures. As polishing eliminated many of the topographical features associated with cpTi-S, cells appeared more fibroblast-like in morphology and had less restricted focal adhesion distribution on polished samples. It is also worth noting that the nanotopographical features of cpTi-PP did appear to support focal adhesion placement at the edges of microstructures while cpTi-EP samples did not appear to hinder spreading. Others have recently demonstrated that size, diameter and spacing of nanostructures can differentially influence cell function through alterations 
in cytoskeletal arrangement and distribution (Berry et al., 2006; Milner and Siedlecki, 2007; Dalby et al., 2008; Biggs et al., 2009; Brammer et al., 2009; Sjöström et al., 2009; González-Garcia et al., 2010; Yim et al., 2010). Therefore, we suggest that the changes in cell morphology may be one of the major contributory factors for the changes observed on an mRNA level in this study. Others have reported a close link between alterations in cell shape and mRNA regulation (Getzenberg, 1994; Chicurel et al., 1998). Briefly, it is postulated that changes in tension of cytoskeletal components, such as focal adhesion sites and the actin and intermediate filament network, directly and indirectly influence signal transduction to the nucleus (Ingber, 1993; Dalby, 2005; Forgacs, 2005). In support of this, others have also recently reported topographical regulation of gene expression, on both nano- and microscales in vitro (Dalby et al., 2002; Harle et al., 2004; Arcelli et al., 2007; Biggs et al., 2009). Furthermore, previous studies from our laboratory have shown that focal adhesion location and maturation can be influenced by surface microtopography leading to alterations in cell behaviour (Meredith et al., 2007). Additional studies are required to confirm our theory.

\section{Conclusion}

We have recently validated in vivo the potential of surface polishing for alleviating removal related morbidity. In this study, we demonstrate that the effect of surface polishing is not purely mechanical. Results from this in vitro study indicate that surface polishing may in part reduce excessive bony over-growth by acting on a molecular level to influence osteoblast 'specific' genes directly involved in osteoblast phenotype and bone regeneration, possibly through surface dependent cell shape alterations.

\section{Acknowledgements}

The authors wish to thank Synthes, Bettlach, Switzerland, for kindly providing the materials used in this study, and Dr V Frauchiger (Robert Mathis Foundation, Bettlach, Switzerland) for XPS measurements.

\section{References}

Alzahrani AG, Behairy YM, Alhossan MH, Arab FS, Alammari AA (2003) Removal of internal fixation devices in pediatric patients. Saudi Med J 24: 254-255.

Arcelli D, Palmieri A, Pezzetti F, Brunelli G, Zollino I, Carinci F (2007) Genetic effects of titanium surface on osteoblasts: A meta-analysis. J Oral Sci 49: 299-309.

Balloni S, Calvi EM, Damiani F, Bistoni G, Calvitti M, Locci P, Becchetti E, Marinucci L (2009) Effects of titanium surface roughness on mesenchymal stem cell commitment and differentiation signaling. Int J Oral Maxillofac Implants 24: 627-635.

Berry CC, Dalby MJ, Oreffo RO, McCloy D, Affrosman S (2006) The interaction of human bone marrow cells with nanotopographical features in three dimensional constructs. J Biomed Mater Res A 79: 431439.
Biggs MJ, Richards RG, Gadegaard N, McMurray RJ, Affrossman S, Wilkinson CD, Oreffo RO, Dalby MJ (2009) Interactions with nanoscale topography: adhesion quantification and signal transduction in cells of osteogenic and multipotent lineage. J Biomed Mater Res A 91: 195208.

Bjursten LM, Rasmusson L, Oh S, Smith GC, Brammer KS, Jin S (2010) Titanium dioxide nanotubes enhance bone bonding in vivo. J Biomed Mater Res A 92: 1218-1224.

Boskey AL, Wians FH Jr, Hauschka PV (1985) The effect of osteocalcin on in vitro lipid-induced hydroxyapatite formation and seeded hydroxyapatite growth. Calcif Tissue Int 37: 57-62.

Boyan BD, Bonewald LF, Paschalis EP, Lohmann CH, Rosser J, Cochran DL, Dean DD, Schwartz Z, Boskey AL(2002) Osteoblast-mediated mineral deposition in culture is dependent on surface microtopography. Calcif Tissue Int 71: 519-529.

Brammer KS, Oh S, Cobb CJ, Bjursten LM, van der Heyde H, Jin S (2009) Improved bone-forming functionality on diameter-controlled $\mathrm{TiO}(2)$ nanotube surface. Acta Biomater 5: 3215-3223.

Brett PM, Harle J, Salih V, Mihoc R, Olsen I, Jones FH, Tonetti M. (2004) Roughness response genes in osteoblasts. Bone 35: 124-133.

Chicurel ME, Singer RH, Meyer CJ, Ingber DE. (1998) Integrin binding and mechanical tension induce movement of mRNA and ribosomes to focal adhesions. Nature 392: 730-733.

Dalby MJ, Yarwood SJ, Riehle MO, Johnstone HJ, Affrossman S, Curtis AS (2002) Increasing fibroblast response to materials using nanotopography: morphological and genetic measurements of cell response to 13-nm-high polymer demixed islands. Exp Cell Res 276: $1-9$.

Dalby MJ (2005) Topographically induced direct cell mechanotransduction. Med Eng Phys 27: 730-742.

Dalby MJ, Andar A, Nag A, Affrossman S, Tare R, McFarlane S, Oreffo RO (2008) Genomic expression of mesenchymal stem cells to altered nanoscale topographies. J R Soc Interface 5: 1055-1065.

Degasne I, Basle M.F, Demais V, Hure G, Lesourd M, Grolleau B, Mercier L, Chappard D (1999) Effects of roughness, fibronectin and vitronectin on attachment, spreading, and proliferation of human osteoblast-like cells (SaOs-2) on titanium surfaces. Calcif Tissue Int 64: 499507.

Ducy P, Zhang R, Geoffroy V, Ridall AL, Karsenty G (1997) Osf2/Cbfa1: a transcriptional activator of osteoblast differentiation. Cell 89: 747-754.

Forgacs G (1995) On the possible role of cytoskeletal filamentous networks in intracellular signaling: an approach based on percolation. J Cell Sci 108: 2131-2143.

Gerber I, ap Gwynn I (2001) Influence of cell isolation, cell culture density, and cell nutrition on differentiation of rat calvarial osteoblast-like cells in vitro. Eur Cell Mater 2: $10-20$.

Getzenberg RH (1994) Nuclear matrix and the regulation of gene expression: tissue specificity. J Cell Biochem 55: 22-31. 
Glowacki J, Lian JB (1987) Impaired recruitment and differentiation of osteoclast progenitors by osteocalcindeplete bone implants. Cell Differ 21: 247-254.

González-García C, Sousa SR, Moratal D, Rico P, Salmerón-Sánchez M (2010) Effect of nanoscale topography on fibronectin adsorption, focal adhesion size and matrix organisation. Colloids Surf B Biointerfaces 77: 181-190

Gordon JA, Tye CE, Sampaio AV, Underhill TM, Hunter GK, Goldberg HA (2007) Bone sialoprotein expression enhances osteoblast differentiation and matrix mineralization in vitro. Bone 41: 462-473.

Gronowicz G, McCarthy MB (1996) Response of human osteoblasts to implant materials: integrin-mediated adhesion. J.OrthopRes 14: 878-887.

Guo J, Padilla RJ, Wallace A, DeKoK IJ, Cooper LF (2007) The effect of hydrofluoric acid treatment of $\mathrm{TiO}_{2}$ grit blasted titanium implants on adherent osteoblast gene expression in vitro and in vivo. Biomaterials 28: 54185425.

Harada H, Tagashira S, Fujiwara M, Ogawa S, Katsumata T, Yamaguchi A, Komori T, Nakatsuka M (1999) Cbfal isoforms exert functional differences in osteoblast differentiation. J Biol Chem 274: 6972-6978.

Harle J, Salih V, Olsen I, Brett P, Jones F, Tonetti M (2004) Gene expression profiling of bone cells on smooth and rough titanium surfaces. J Mater Sci Mater Med 15: 1255-1258.

Hayes JS, Vos DI, Hahn J, Pearce SG, Richards RG (2009) An in vivo evaluation of surface polishing of TAN Intramedullary Nails for ease of removal. Eur Cell Mater 18: $15-26$.

Hayes JS, Seidenglanz U, Pearce SG, Archer CW, Richards RG(2010) Surface polishing positively influences ease of fracture fixation plate \& screw removal. Eur Cell Mater 19: 117-126.

Hayes JS, Richards RG (2010) Surfaces to control tissue adhesion for osteosynthesis with metal implants: in vitro and in vivo studies to bring solutions to the patient. Expert Rev. Med. Devices 7: 131-142.

Hunter GK, Hauschka PV, Poole AR, Rosenberg AR, Goldberg HA (1996) Nucleation and inhibition of hydroxyapatite formation by mineralized tissue proteins.

Biochem J 317: 59-64.

Ingber DE (1993) Cellular tensegrity: defining new rules of biological design that govern the cytoskeleton. J Cell Sci 104: 613-627.

Isa ZM, Schneider GB, Zaharias R, Seabold D, Stanford CM (2006) Effects of fluoride-modified titanium surfaces on osteoblast proliferation and gene expression. Int J Oral Maxillofac Implants 21: 203-211.

Kieswetter K, Schwartz Z, Hummert TW, Cochran DL, Simpson J, Dean DD, Boyan BD (1996) Surface roughness modulates the local production of growth factors and cytokines by osteoblast-like MG-63 cells. J.Biomed.Mater Res 32: 55-63.

Komori T, Yagi H, Nomura S, Yamaguchi A, Sasaki K, Deguchi K, Shimizu Y, Bronson RT, Gao YH, Inada M, Sato M, Okamoto R, Kitamura Y, Yoshiki S, Kishimoto $\mathrm{T}$ (1997) Targeted disruption of Cbfa1 results in a complete lack of bone formation owing to maturational arrest of osteoblasts. Cell 89: 755-764.

Lamour V, Detry C, Sanchez C, Henrotin Y, Castronovo V, Bellahcène A (2007). Runx2- and histone deacetylase 3-mediated repression is relieved in differentiating human osteoblast cells to allow high bone sialoprotein expression. J Biol Chem 282: 36240-36249.

Lian JB, Stein GS (1992). Concepts of osteoblast growth and differentiation: basis for modulation of bone cell development and tissue formation. Critical Rev Oral Biol Med 3: 269-305.

Livak KJ, Schmittgen TD (2001) Analysis of gene expression data using real-time quantitative PCR and the $2^{-\Delta \Delta \mathrm{CT}}$ method. Methods 25: 402-408.

Lohmann CH, Tandy EM, Sylvia VL, Hell-Vocke AK, Cochran DL, Dean DD, Boyan BD, Schwartz Z (2002) Response of normal female human osteoblasts (NHOst) to 17 beta-estradiol is modulated by implant surface morphology. J Biomed.Mater Res 62: 204-213

Martin JY, Schwartz Z, Hummert TW, Schraub DM, Simpson J, Lankford Jr J, Dean DD, Cochran DL, Boyan BD (1995) Effect of titanium surface roughness on proliferation, differentiation and protein synthesis of human osteoblast-like cells (MG-63) J Biomed Mater Res 29: 389-401.

Martin JY, Dean DD, Cochran DL, Simpson J, Boyan BD, Schwartz Z (1996) Proliferation, differentiation, and protein synthesis of human osteoblast-like cells (MG63) cultured on previously used titanium surfaces. Clin Oral Implants Res 7: 27-37.

Masaki C, Schneider GB, Zaharias R, Seabold D, Stanford C (2005) Effects of implant surface microtopography on osteoblast gene expression. Clin Oral Implants Res 16: 650-656.

Mendonça G, Mendonça DB, Aragão FJ, Cooper LF (2010) The combination of micron and nanotopography by $\mathrm{H}(2) \mathrm{SO}(4) / \mathrm{H}(2) \mathrm{O}(2)$ treatment and its effects on osteoblast-specific gene expression of hMSCs. J Biomed Mater Res A, in press.

Meredith DO, Eschbach L, Riehle MO, Curtis AS, Richards RG (2007) Microtopography of metal surfaces influence fibroblast growth by modifying cell shape, cytoskeleton, and adhesion. J Orthop Res 25: 1523-1533.

Milner KR \& Siedlecki CA (2007) Fibroblast response is enhanced by poly (L-lactic acid) nanotopography edge density and proximity. Int J Nanomedicine 2: 201-211.

Nakashima K, Zhou X, Kunkel G, Zhang Z, Deng JM, Behringer RR, de Crombrugghe B(2002) The novel zinc finger-containing transcription factor osterix is required for osteoblast differentiation and bone formation. Cell 108: $17-29$.

Olivares-Navarrete R, Hyzy SL, Hutton DL, Erdman CP, Wieland M, Boyan BD, Schwartz Z (2010) Direct and indirect effects of microstructured titanium substrates on the induction of mesenchymal stem cell differentiation towards the osteoblast lineage. Biomaterials 31: 27282735 .

Otto F, Thornell AP, Crompton T, Denzel A, Gilmour KC, Rosewell IR, Stamp GW, Beddington RS, Mundlos S, Olsen BR, Selby PB, Owen MJ (1997) Cbfa1, a 
candidate gene for cleidocranial dysplasia syndrome, is essential for osteoblast differentiation and bone development. Cell 89: 765-771.

Pearce AI, Pearce SG, Schwieger K, Milz S, Schneider E, Archer CW, Richards RG (2008) Effect of surface topography on removal of cortical bone screws in a novel sheep model. J Orthop Res 26: 1377-1383.

Peterson HA (2005) Metallic implant removal in children. J Pediatr Orthop 25: 107-115.

Schlegel P, Hayes JS, Frauchiger VM, Wieling R, Textor M, Richards RG (2009) An in vivo evaluation of the biocompatibility of anodic plasma chemical treatment with calcium phosphate of titanium. J Biomedical Res Part B 90: 26-34.

Schneider GB, Perinpanayagam H, Clegg M, Zaharias R, Seabold D, Keller J, Stanford C (2003) Implant surface roughness affects osteoblast gene expression. J Dent Res 82: $372-376$.

Schneider GB, Zaharias R, Seabold D, Keller J, Stanford C (2004) Differentiation of preosteoblasts is affected by implant surface microtopographies. J Biomed Mater Res A 69: 462-468.

Sjöström T, Dalby MJ, Hart A, Tare R, Oreffo RO, Su B (2009) Fabrication of pillar-like titania nanostructures on titanium and their interactions with human skeletal stem cells. Acta Biomater 5: 1433-1441.

Welton JL (2007)M.Sc. Thesis: In vivo evaluation of defined polished surfaces to prevent soft tissue adhesion. AO Research Institute, Davos, Switzerland.

Yang Y, Cavin R, Ong JL (2003) Protein adsorption on titanium surfaces and their effect on osteoblast attachment. J Biomed Mater Res A 67: 344-349.

Yim EK, Darling EM, Kulangara K, Guilak F, Leong KW (2010) Nanotopography-induced changes in focal adhesions, cytoskeletal organization, and mechanical properties of human mesenchymal stem cells. Biomaterials 31: 1299-1306.

\section{Discussion with Reviewer}

Reviewer I: It appears that focal adhesions were formed on the edges of microstructures on cpTI-PP substrates and not on cpTi-EP ones. Do the authors attribute this difference to a topography presenting mainly convex microstructures (pits) on cpTI-PP substrates and mainly concave microstructures (peaks) on cpTi-EP ones? Could it be related to a difference in mean lateral dimensions of the microstructures or in spacing between microstructures?

Authors: Since surface chemistry is similar for all samples, we agree with the reviewer that surface nanotopography may attribute to the in vitro differences observed between polished samples via focal adhesion distribution. As outlined by the reviewer, it is likely that the spacing, size and diameter of the nano-structures would have a role to play. In fact, several recent studies have investigated these parameters (Berry et al., 2006; Milner and Siedlecki, 2007; Dalby et al., 2008; Brammer et al., 2009; Sjostrom et al., 2009; Biggs et al., 2009). While the role of nanotopography in vitro cannot be ignored, only preliminary data regarding the extent of this influence in vivo is available (Bjursten et al., 2010). In contrast, it is well known that micro-structures can influence cell and tissue responses. In support of this, we have also recently validated the effect of polishing in vivo (Hayes et al., 2009; Hayes et al., 2010).

Reviewer I: Anodization process is known to influence as well nanotopography as surface chemistry. Could this treatment induce different surface modifications on cpTi and polished ones that could explain the differences observed in term of cell adhesion and gene expression?

Authors: As mentioned, anodisation was employed within the context of this study as a final processing step for increasing the surface oxide (similar to implant materials used in clinics). Consequently, no differences in surface chemistry between samples were observed. However, the reviewer is correct in their suggestion that this process can be used as a surface modification technique to induce changes to surface topography. In fact, some recent studies have employed anodisation to investigate the effect of patterned and random surface morphologies on cell function (Brammer et al., 2009; Sjostrom et al., 2009). This was not the intended outcome of the inclusion of this process in this study, however, we accept that if the treatment did inadvertently induce surface topographical changes that these may contribute to the differences observed. However, we maintain that the main changes in topography were induced by polishing, and effectively the changes induced by the electrochemical and mechanical influence of these polishing techniques are responsible for the key changes in surface features, and ultimately, the cell responses observed. 